\title{
Codes of ethics, human rights and forced migration
}

\section{Ryan Essex}

Research Fellow, Institute for Lifecourse Development, The University of Greenwich r.w.essex@gre.ac.uk

Codes of medical ethics have a range of fundamental limitations, London (2020) suggests that they have two fundamental flaws; how they deal with uncertainty and failing to address the role of advertising in healthcare. While I agree these are major concerns, the limitations of codes of ethics can be seen elsewhere. This article will consider the relationship between codes of ethics and force migration; in particular situations in which healthcare professionals may be proximate or involved in human rights violations, such as immigration detention centres. I will expand on London's (2020) identification of "individualism" within codes as problematic. I will argue that while codes often utilise the language of human rights their focus on individual healthcare professionals and patients often comes at the cost of guiding broader social, institutional and structural reform. To address these issues we will not only need to reform codes, but look beyond them. That is, the healthcare professions also need to begin to think about the organisational, institutional and structural change that is needed, not only to enable the most ethical choices to be made, but in working toward a more just world. 


\section{Codes of ethics, human rights and forced migration}

The COVID-19 pandemic has led to the largest sudden global change to community life in living memory. Since being declared a pandemic in early 2020, there has been a growing body of evidence that has shed light on the impact of COVID-19 on health and wellbeing around the globe. COVID-19 has also highlighted number of shortcomings with existing codes of ethics and how these are applied. London and West (2020) argue that codes of ethics fail to offer explicit guidance when there is uncertainty about treatment and interventions, which can be in many cases counterproductive and self-defeating as this impedes the conduct of "socially valuable medical research". They also argue that the failure to address medical advertising, often puts patient preference in conflict with professional norms such as fidelity and transparency. These issues are exacerbated by codes focus on individual actors, whether this be the healthcare professional or patients, and while these shortcomings have been foregrounded by COVID-19, they have far greater implications. Below, I want to expand on these observations. I first consider similar discussions that have been had in parallel in relation to forced migration and immigration detention, outlining the limitations of codes in this context. In seeking to address these shortcomings, I will argue that because of the individuality of codes, along with their more fundamental limitations, we not only need to look at codes of ethics, but beyond, toward broader institutional, social and structural change; change that provides greater opportunity to act ethically and reduces uncertainties in decision making.

In addition to COVID-19 the world continues to face a number of crises; climate change continues to present an existential threat, poverty impacts millions, while violence and persecution remain common. Related to each of these things, forced migration is a particularly pressing issue. In 2019, there were 79.5 million people forcibly displaced worldwide (UNHCR 2020). Forced displacement is a broad term and can be used to describe the movement of a range of groups; refugees, those displaced by disasters, those impacted by poverty and even victims of trafficking. The majority of those who are displaced remain within their own or neighbouring country, however a small but significant number also attempt to find safety elsewhere, often crossing borders, travelling from the global South to the global North. In the US, immigration detention has created untold misery and resulted in numerous deaths. As well as separating children from their families, US immigration detention has seen the death of a number of people, including children, at least three of whom have died from preventable causes 
(Arzuaga 2020). In the UK, under the governments aptly named 'hostile environment' policies, identity checks and upfront charging have been made obligatory for health services. Those without documentation are now unable to access a range of services. Furthermore, the government has also pushed a number of data-sharing arrangements, within the National Health Service (NHS) and with other public services, using patient data from the NHS for immigration enforcement purposes (Bulman 2019). In Australia, refugees and asylum seekers have been now held offshore on Manus Island (Papua New Guinea) and Nauru for over 7 years. These policies have had a devastating impact on detainees (Essex 2016), leading the International Criminal Court (ICC) to label these policies as cruel, inhuman and degrading (Doherty 2020). In all instances, healthcare professionals have been closely involved, working within centres and protesting the consequences of these policies.

While each of the above examples is somewhat different, each raises a similar ethical issue for healthcare professionals working in close proximity, namely how to reconcile the obligation to act in the best interests of their patients while being co-opted to act as a de-facto border guard (as is the case in the UK) or facilitate policies that clearly harm health. There are no straightforward answers for such dilemmas in codes of ethics. Often labelled 'dual loyalty' conflicts, the advice often given is to reconcile such dilemmas by placing the interests of the patients first; it simply isn't clear how this can be accomplished or how this should be negotiated day to day (Essex 2019). Detention centres raise further questions about the rights and dignity of patients and the standard of healthcare provided within detention. What is ethical care for a child when they are separated from their parents? What does autonomy mean for people who are detained? Is beneficence a matter of healthcare as usual or advocating for a patients release? How do we square this with generally accepted norms to uphold human rights and dignity? We could say that given the circumstances, healthcare professionals should still do their best to promote the health of their patients and minimise their contribution to any wrongdoing. If faced with two bad options, healthcare professionals should obviously take the one which will do the least harm, such statements however often overlook the potential for broader reform and for those who remain detained (or in a liminal state), are woefully inadequate (Essex 2018).

This leads to the next point, the individual nature of codes. The problem with this focus is that it often comes at the cost of guiding broader social, institutional and structural reform. Structures, organisations and institutions enable and constrain the choices we have. That is, we 
often can only work within existing rules, structures and systems; we can only provide healthcare within the constraints set out by government or our employer, for example. While codes of ethics often utilise the language of human rights and reference healthcare professionals broader obligations to society, they often fail to provide advice related to challenging the structural and institutional forces that lead to human rights violations, leaving individual clinicians powerless to address these issues. Put another way, while healthcare professionals should put their patients interests first given the circumstances, shouldn't we, in the first instance, aim to change the circumstances that threaten the rights of our patients.

In addition to individuality, there are two more fundamental limitations of codes, that explain not only the issues raised by London and West (2020) but why codes have little to offer healthcare professionals dealing with the issue of forced migration and immigration detention. While codes of ethics could serve a number of purposes (and more on this below) when we approach codes as a set of rules or principles written prospectively to guide behaviour, Dawson (1994) argues codes of ethics have two fundamental limitations. First, codes of ethics cannot account for previously unforeseen situations. No code can account for all possible future scenarios, nor can any principle be applied in all potential circumstances. Practically this means that healthcare professionals may be placed in a situation where "some ethical response is appropriate, but none of the rules seems to be relevant" (p. 148). Second, principles and statements found within codes can conflict. Together this results in codes of ethics not having an answer for every given scenario and even offering conflicting advice, resulting in uncertainty when faced with unprecedented or unforeseen situations. These more fundamental limitations of codes, along with their individual focus speak to another issue, namely, the purpose of codes of ethics. Banks (2003) for example suggests that codes also serve as rhetorical, educational and regulatory devices as much as they are guides for healthcare professionals. If we accept that their primary function is to guide behaviour, we could look at doing one of a few things to overcome the issues above. We could of course amend or add guidance, address conflicts and clarify contradictions, we could even also write codes more broadly, being more explicitly about the role that healthcare professionals could play in structural change and what should be done for those who are forcibly displaced. As can be imagined however, writing a code in such a way risks becoming overly lengthy and complex, and even then, codes would remain constrained by the above limitations. 
An alternative would be to look elsewhere as to how we could guide behaviour. Dawson (1994) for example suggests a cognitive account of ethical conduct, that is, ethical action that is not judged against a particular rule, but how healthcare professionals respond to unique circumstances, along with their ability to modify their behaviour, be open to experience, advice and criticism; using experience to adjust their behaviour to any given circumstance. Beyond the individual however, we also need to begin to think about the change that is needed to our organisations, institutions and structures. We will never be able to pre-empt every situation or avoid ethical conflicts, however if we look beyond codes of ethics and achieve broader structural change, we could do a great deal to minimise future dilemmas. Such a shift would not only to enable the most ethical choices to be made, but will be critical in working toward a more just world. Such a world where we are better prepared for future pandemics, and where we treat others, even those beyond our borders, with dignity.

\section{References}

Arzuaga, Bonnie. 2020. "Suffering Children and Handcuffed Doctors: US Immigration Policy and a Call for Advocacy." Pediatrics: e20200495-e20200495.

Banks, Sarah. 2003. "From oaths to rulebooks: A critical examination of codes of ethics for the social professions." European Journal of Social Work 6 (2): 133-144.

Bulman, M. 2019. Home Office still using NHS patient data for immigration enforcement despite suggesting it would end practice. Independent. https://www.independent.co.uk/news/uk/home-news/home-office-nhs-data-sharingimmigration-enforcement-a8761396.html

Dawson, Angus. 1994. "Professional codes of practice and ethical conduct." Journal of Applied Philosophy 11 (2): 145-153.

Doherty, B. 2020. "Australia's offshore detention is unlawful, says international criminal court prosecutor." The Guardian. https://www.theguardian.com/australianews/2020/feb/15/australias-offshore-detention-is-unlawful-says-internationalcriminal-court-prosecutor.

Essex, Ryan. 2016. "Healthcare and clinical ethics in Australian offshore immigration detention." The International Journal of Human Rights 20 (7): 1039-1053.

---. 2018. "Psychology and its Response to Major Human Rights Abuses: The Case of Australian Immigration Detention." European Psychologist. 
---. 2019. "Do codes of ethics and position statements help guide ethical decision making in Australian immigration detention centres?" BMC medical ethics 20 (1): 52.

London, A J, and C L West. 2020. "Self-Defeating Codes of Medical Ethics and How to Fix Them: Failures in COVID-19 Response and Beyond." American Journal of Bioethics. UNHCR. 2020. "Global trends: Forced displacement in 2019." https://www.unhcr.org/globaltrends2019/. 